\title{
Variance in Heart Rate And Maximum Predicted Heart Rate on Stress Test with Changing Body Mass index in Young And Middle Old Age Individuals
}

\author{
Dr.Cleofina Furtado ${ }^{1}$, Dr.Sandip Sardessai ${ }^{2}$ \\ 1post Graduate, Goa Medical College, Bambolim, Goa, India. \\ 2 department Of Physiology, Goa Medical College, Bambolim, Goa, India.
}

\begin{abstract}
:
Aim: Decrease in physical activity has led to rise in obesity contributing to the upward trend of cardiovascular disease. This study aims to find how the alteration in body mass index (BMI) results in heart rate (HR) and percentage of maximum predicted heart rate (\% max pHR) variability and how it differs in young and middle old subjects before and after thestress test. Also it aims to find the same difference between type 2 diabetics (type 2 DM) and non-diabetic (non DM); secondary hypertensive (HTN) and non-hypertensive (non HTN)individuals.

Method: 120 individuals in the age range 14 to 75 years of age were taken for this study. We grouped these individuals into young and middle-old which was further subdivided into underweight, normal, overweight, obese based on BMI.Also the middle-old age group was by itself divided into hypertensive and non-hypertensive, type 2 diabetic and non-diabetic. The individuals were asked to undergo the stress test on a treadmill. The test was terminated on achieving the max predicted heart rate or on complaints of fatigue, leg discomfort or chest pain. Heart rate, and percentage of maximum predicted heart rate was recorded at rest and at the end of exercise.
\end{abstract}

Outcome: it was found that on doing stress test HR was increased in all groups. But the increase was significantly more in young individuals especially in underweight and normal BMI groups.

Keywords: BMI, Overweight, obesity, type 2 diabetes, secondary hypertension.

\section{Introduction}

It is estimated that cardiovascular disease will result in over 40 per cent deaths in India in 2020 as compared to 24 per cent in 1990(1). With over 3 million deaths in a year, India would be the capital of cardiovascular in the upcoming years(1). Worldwide, it results in 17.3 million deaths in a year(1).It has claimed to be the leading cause in both rural and urban and also show a rising trend, with the rural slope lesser as compared to the urban(2). Cardiovascular disease ranks the highest in non-communicable disease among both males and females and in all regions in India (2)

There have been studies conducted to find the association between BMI and cardiovascular status , and the effect of physical activity on cardiovascular functioning(3-10). The research on various cardiovascular parameters, the mechanism of cardiac cycle have resulted in finding out the determinants associated with the alteration of the normal working capacity and capability of heart. However there is paucity of data in terms of comparative study in young and middle old in terms of B MI variability. So also the data on association of type 2 DM and HTN and BMI is very scarce.

The aim of this study was to determine the variability between HR, and percentage of max pHRand BMI at rest and on exercise. Also we studied whether there was any correlation in these variables between young and middle old age subjects i.e. age dependency .we hypothesized 1)that increase in BMI lead to decrease in cardiovascular fitness 2) increase in age results in higher decrease in cardiovascular functioning irrespective of BMI.We also investigated whether HTN and type 2 DM had the same implication of deteriorating the cardiovascular status as that of BMI.

\section{Participants And Study Design}

This is a cross sectional comparative study. The participants were selected randomly. 120 individuals undertook the test of which 78 were males and 43 females. The combined total of non-DMHTN subjects were $(\mathrm{n}=61)$. The participants were subdivided into young and middle-old age of which young were $(n=29)$ and middle old $(n=32)$. The confounding factor of DM (type 2 DM) and HTN was adequately matched while comparing between BMI. Subjects with $20.45 \pm 3.9$ years were grouped as young with the highest being 26 years $(n=14)$. The middle age consisted with their age ranging from 31 - 
Variance in heart rate and maximum predicted heart rate on stress test with changing bod...

75 years $(51.03 \pm 9.7)$ of which non- type 2 diabetic-hypertensive (non DM-HTN) consisted of $(n=32)$ subjects with age range between 31-65 years.

The test was performed during July 2014 to mid-September 2014. The test was undertaken according to protocols of the ethical committee of the institution. Some participants in the middle -old age were selected from the outpatient department, goa medical college, Bambolim, Goa, India (tertiary care centre) who came for follow up of their medical ailment, with history of hypertension, diabetes, as a part of routine investigation. While others in the middle-old age and young volunteered to perform the test. Consent was taken from the participants before starting the test after explaining about the test verbally.

The test was undertaken according to guidelines of American college of cardiology. Prior to starting the test history was asked regarding past history, and personal history, and drug history. Depending on past history, middle-old were further sub divided into non-diabetic--hypertensive $(\mathrm{n}=32)$ with normal BMI $(n=14)$ and overweight BMI $(n=9)$, underweight $(n=3)$, and obese $(n=6)$; secondary hypertensive with normal BMI were $(n=16)$, and with overweight $\mathrm{BMI}(\mathrm{n}=13)$; while type 2 diabeticshypertension with normal BMI $(\mathrm{n}=17)$ and the same with overweight $\mathrm{BMI}(\mathrm{n}=10)$ to compare how they would affect the cardiovascular functioning in normal and overweight bmi.

The weight was measured on an automated weighing machine scale. Height was measured using a stadiometer. BMI was calculated based on the anthropometric measurements. Electrodes were placed on chest to measure the heart rate and ECG .Heart rate was measured at rest after sitting for a min and then again was measured after standing for a min. Participants were explained about the procedure of the test. Test was conducted under supervision and guidance of doctor and para medics. Participants were asked to walk on the treadmill. The test consisted of 4 stages. Each stage was of 3 mins. During each stage heart rate, was measured with an ECG was taken. During the first stage speed was $2.7 \mathrm{~km} / \mathrm{hr}$ and grade of inclination $10 \%$, during second speed was $4 \mathrm{~km} / \mathrm{hr}$ and grade $12 \%$, during third speed and grade was $5.4 \mathrm{~km} / \mathrm{hr}$ and $14 \%$ respectively while during third it was $6.7 \mathrm{~km} / \mathrm{hr}$ speed and inclination grade $16 \%$.Test was terminated if the patient had symptoms of chest pain, fatigues, and leg discomfort, or on achieving the max predicted or on completion of 4 stages. Max predicted heart was calculated by means of the formula max heart rate/220- age of the participant (11). 220-age gives the targeted heart rate.

Individuals were grouped as underweight $(\mathrm{n}=3)$, normal(14), overweight $(\mathrm{n}=9)$, and obese $(\mathrm{n}=3)$ depending on their BMI In young and underweight $(n=3)$, normal(n14), overweight $(n=9)$, obese $(n=3)$ in middle old. According to cut off points provided by WHO classification 1995.

Table.1.1 Physical characteristics of subjects

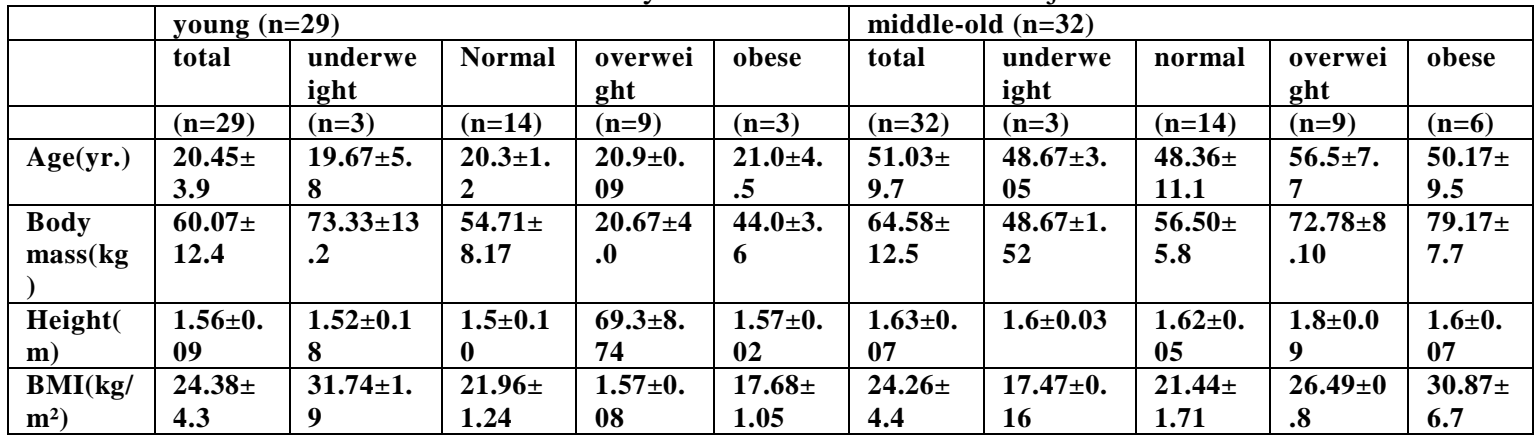

Data are mean \pm SD. BMI-body mass index.*p $\leq 0.05, * * p \leq 0.01, * * * p \leq 0.0001$. These symbols indicate level of significant difference between BMI is calculated using unpaired student $t$ test.

\section{Statistical Analysis}

All the results were tabulated. Statistical analysis was done according to graph pad prism SPSS version 6.01.At first HR was compared between pre-test and at the end of the test. Student unpaired test was used to find the significance. Values below $p \leq 0.05$ were considered significant, $p \leq 0.01$ very significant, $\mathrm{p} \leq 0.0001$ very highly significant. Correlation coefficient was trivial $(\mathrm{r}<0.1)$, small $(\mathrm{r} 0.1-0.3)$, moderate ( $\mathrm{r} 0.3-0.5)$, large $(\mathrm{r} 0.5-0.7)$, nearly perfect $(\mathrm{r}>0.9)$ and perfect $(\mathrm{r}=1)(3)$.

The pre-test variables (HR) was compared with BMI in young and middle-old and their p value of significance was found using one way ANOVA (non-parametric test). Also the correlation between them was found by Karl Pearson product moment. The mean \% change in the variable (HR) was compared with young and middle old and their $\mathrm{p}$ value and $\mathrm{r}$ value was found using the above test. The mean $\%$ change was found calculating the mean\% change in the variable for each individual and then their mean was taken. The $\%$ max predicted HR rate (\% man pHR), and wascompared. The pre-test and 
Variance in heart rate and maximum predicted heart rate on stress test with changing bod...

mean $\%$ change of HR was compared between non-diabetic--non hypertensive and diabetic, and between non-diabetic--hypertensive and hypertensive individuals in both normal \& overweight BMI and their value of significant difference was calculated using student $t$ test.

The mean \% change of HR was also compared between young and middle-old in normal \& overweight $\mathrm{BMI}$ and the significant difference was calculated using t test.

\section{Results}

Table.1.2 Comparison between pre-test \& after exercise heart rate in young with underweight normal overweight and obese BMI

\begin{tabular}{|l|l|l|l|l|l|l|}
\hline \multicolumn{6}{|l|}{ young $(\mathrm{n}=29)$} \\
\hline & underweight BMI $(\mathrm{n}=3)$ & \multicolumn{1}{l|}{ normal BMI $(\mathrm{n}=14)$} & \\
\hline & pre-test & exercise & p value & pre-test & exercise & p value \\
\hline HR & $84.0 \pm 3.46$ & $180.7 \pm 6.0$ & $<0.0001 * * *$ & $77.36 \pm 5.7$ & $182.1 \pm 11.7$ & $<0.0001 * * *$ \\
\hline & & & & & & \\
\hline
\end{tabular}

\begin{tabular}{|c|c|c|c|c|c|c|}
\hline \multicolumn{7}{|c|}{ young $(n=29)$} \\
\hline & \multicolumn{3}{|c|}{ overweight BMI(n=9) } & \multicolumn{3}{|c|}{ obese BMI $(\mathrm{n}=3)$} \\
\hline & pre-test & exercise & $\mathrm{p}$ value & pre-test & exercise & $\mathrm{p}$ value \\
\hline HR & $92.11 \pm 3.9$ & $140.2 \pm 13.35$ & $<0.0001 * * *$ & $86.6 \pm 3.21$ & $141.3 \pm 7.3$ & $0.0003 *$ \\
\hline
\end{tabular}

Data are mean \pm SD. HR-heart rate, BMI-body mass index. .*p $\leq 0.05$ significant, $* * p \leq 0.01$ very significant,

$* * * p \leq 0.0001$ very highly significant. These symbols indicate level of significant difference between BMI.

It is calculated using unpaired student $t$ test.

Table.1.3 Comparison between pre-test \& after exercise heart rate in middle old with underweigh,t

Normal, overweight and obese BMI

\begin{tabular}{|c|c|c|c|c|c|c|}
\hline \multicolumn{7}{|c|}{ middle-old(n=32) } \\
\hline & \multicolumn{3}{|c|}{ underweight $\mathrm{BMI}(\mathrm{n}=3)$} & \\
\hline & pre-test & \multicolumn{2}{|l|}{ exercise } & \multicolumn{3}{|c|}{\begin{tabular}{l|l} 
pre-test & exercise
\end{tabular}} \\
\hline HR & $80.03 \pm 8.6$ & $165.0 \pm 12.17$ & $<0.0001 * * *$ & $74.57 \pm 10.8$ & $155.1 \pm 17.65$ & $<0.0001^{* * * *}$ \\
\hline \multicolumn{7}{|c|}{ middle-old(n=32) } \\
\hline & \multicolumn{3}{|c|}{ overweight $\mathrm{BMI}(\mathrm{n}=9)$} & \multicolumn{3}{|l|}{ obese BMI(n=6) } \\
\hline & pre-test & exercise & $\mathrm{p}$ value & pre-test & exercise & $\mathrm{p}$ value \\
\hline$\overline{\mathrm{HF}}$ & $83.6 \pm 16.0$ & $145.3 \pm 22.7$ & $<0.0001^{* * * *}$ & $91.17 \pm 7.13$ & $143.0 \pm 18.18$ & $<0.0001$ **** \\
\hline
\end{tabular}

Data are mean \pm SD. HR-heart rate, BMI-body mass index. .*p $\leq 0.05$ significant, **p $\leq 0.01$ very significant,

$* * * p \leq 0.0001$ very highly significant. These symbols indicate level of significant difference between BMI.

It is calculated using unpaired student $t$ test.

Table .1.4 Comparison of pre-test values of heart rate and \% max pHRbetween BMI in young and middle old

\begin{tabular}{|l|l|l|l|l|l|l|}
\hline young $(\mathrm{n}=29)$ & underweight & normal & overweight & obese & P value & $\begin{array}{l}\mathrm{r} \\
\text { value }\end{array}$ \\
\hline & & & & & & \\
\hline HR & $84.03)$ & $(\mathrm{n}=14)$ & $(\mathrm{n}=9)$ & $(\mathrm{n}=3)$ & & \\
\hline \% $\max \mathrm{p}(\mathrm{HR})$ & $90.8 \pm 2.8$ & $77.36 \pm 5.7$ & $92.11 \pm 3.9$ & $86.67 \pm 3.21$ & $<0.0001^{* * * *}$ & 0.457 \\
\hline
\end{tabular}

\begin{tabular}{|c|c|c|c|c|c|c|}
\hline \multicolumn{7}{|c|}{ middle-old $(\mathrm{n}=32)$} \\
\hline & underweight & normal & overweight & obese & $\mathrm{p}$ value & $\mathrm{r}$ value \\
\hline & $(\mathrm{n}=3)$ & $(n=14)$ & $(\mathrm{n}=9)$ & $(n=6)$ & & \\
\hline HR & $80.33 \pm 8.6$ & $74.57 \pm 10.8$ & $83.6 \pm 16.00$ & $91.17 \pm 7.13$ & $0.0489 *$ & 0.4 \\
\hline$\% \max \mathrm{p}(\mathrm{HR})$ & $96.35 \pm 7.77$ & $89.25 \pm 10.13$ & $88.8 \pm 12.44$ & $85.97 \pm 10.5$ & 0.6051 & -0.476 \\
\hline
\end{tabular}

Data are mean \pm SD. HR-heart rate, BMI-body mass index. pHR- predicted heart rate. $* \mathrm{p} \leq 0.05$ significant, $* * \mathrm{p} \leq 0.01$ very significant, $* * * \mathrm{p} \leq 0.0001$ Very highly significant. 
Variance in heart rate and maximum predicted heart rate on stress test with changing bod...

These symbols indicate level of significant difference between BMI. It is calculatedusing one way ANOVA

(non parametric) test. $\mathrm{r}$ value indicates the degree of correlation calculated by Karl Pearson product moment

Table .1.5 Comparison of mean \% change in heart rate (difference between after exercise and pre-test), between BMI in young and middle old

\begin{tabular}{|l|l|l|l|l|l|l|}
\hline \multicolumn{6}{|l|}{ young(n=29) } \\
\hline & underweight & normal & overweight & obese & P value & r value \\
\hline & $(\mathrm{n}=3)$ & $(\mathrm{n}=14)$ & $(\mathrm{n}=9)$ & $(\mathrm{n}=3)$ & & \\
\hline HR & $43.39 \pm 2.50$ & $47.38 \pm 3.57$ & $25.53 \pm 5.5$ & $29.53 \pm 3.7$ & $<0.0001 * * *$ & -0.8 \\
\hline
\end{tabular}

\begin{tabular}{|l|l|l|l|l|l|l|}
\hline \multicolumn{1}{|l|}{ middle-old(n=32) } \\
\hline & underweight & normal & overweight & obese & p value & r value \\
\hline & $(\mathrm{n}=3)$ & $(\mathrm{n}=14)$ & $(\mathrm{n}=9)$ & $(\mathrm{n}=6)$ & & \\
\hline HR & $41.34 \pm 2.37$ & $41.0 \pm 7.93$ & $33.01 \pm 8.03$ & $26.99 \pm 8.06$ & $0.0004 * *$ & -0.5386 \\
\hline
\end{tabular}
significant,

Data are mean \pm SD. HR-heart rate, BMI-body mass index. .*p $\leq 0.05$ significant, **p $\leq 0.01$ very $* * * \mathrm{p} \leq 0.0001$ very highly significant.These symbols indicate level of significant difference between BMI. It is calculated using one way ANOVA (non parametric) test.

$\mathrm{r}$ value indicates the degree of correlation calculated by Karl Pearson product moment

Table .1.6 Comparison of pre-test value in heart rate and \% max pHR between non diabetic-hypertensive $\&$ hypertensive and between non diabetic-hypertensive \& diabetic in normal and overweight BMI middle old subjects

\begin{tabular}{|l|l|l|l|l|l|l|}
\hline \multicolumn{2}{|l|}{ middle-old(n=52) } & \multicolumn{2}{l|}{ overweight BMI(n=22) } \\
\hline & normal BMI(n=30) & hormal & hypertensive & $\mathrm{p}$ value \\
\hline & normal & hypertensive & p value & nol & $(\mathrm{n}=13)$ & \\
\hline & $(\mathrm{n}=14)$ & $(\mathrm{n}=16)$ & & $(\mathrm{n}=9)$ & $77.46 \pm 10.4$ & 0.2833 \\
\hline HR & $74.57 \pm 10.8$ & $76.94 \pm 13.6$ & 0.6071 & $83.6 \pm 16.0$ & $87.15 \pm 10.30$ & 0.7375 \\
\hline \%max p(HR) & $89.82 \pm 16.34$ & $85.24 \pm 10.32$ & 0.2929 & $88.81 \pm 12.44$ & 874 \\
\hline
\end{tabular}

\begin{tabular}{|l|l|l|l|l|l|l|}
\hline middle-old(n=50) & \multicolumn{5}{l|}{} \\
\hline & \multicolumn{2}{|l|}{ normal BMI(n=31) } & \multicolumn{3}{l|}{ overweight BMI(19) } \\
\hline & normal & DM & p value & normal & $\begin{array}{l}\mathrm{p} \\
\text { value }\end{array}$ \\
\hline & $(\mathrm{n}=14)$ & $17)$ & & $(\mathrm{n}=9)$ & $(\mathrm{n}=10)$ & \\
\hline HR & $74.57 \pm 10.8$ & $86.12 \pm 11.44$ & $0.0077 * *$ & $83.6 \pm 16.0$ & $85.7 \pm 18.2$ & 0.8002 \\
\hline \%max p(HR) & $89.82 \pm 16.34$ & $89.8 \pm 16.3$ & 0.9094 & $88.81 \pm 12.44$ & $92.60 \pm 6.78$ & 0.4142 \\
\hline
\end{tabular}

Data are mean \pm SD. HR-heart rate, BMI-body mass index. pHR-predicted heart rate.

$* p \leq 0.05$ significant, $* * p \leq 0.01$ very significant, $* * * p \leq 0.0001$ very highly significant. These symbols indicate

level of significant difference between BMI.It is calculated using unpaired student t test.

Table .1.7 Comparison of mean \% change of in heart rate between non diabetic-hypertensive \& hypertensive and between non diabetic-hypertensive \& diabeticin normal and overweight BMI middle old subjects

\begin{tabular}{|l|l|l|l|l|l|l|}
\hline \multicolumn{6}{|l|}{ middle-old(n=52) } \\
\hline & normal BMI(n=30) & \multicolumn{4}{l|}{ overweight BMI(n=22) } \\
\hline & normal & hypertensive & p value & normal & hypertensive & p value \\
\hline & $(\mathrm{n}=14)$ & $(\mathrm{n}=16)$ & & $(\mathrm{n}=9)$ & $(\mathrm{n}=13)$ & \\
\hline HR & $41.00 \pm 7.9$ & $34.72 \pm 7.58$ & $0.0255^{*}$ & $33.01 \pm 8.03$ & $34.55 \pm 10.9$ & 0.7235 \\
\hline
\end{tabular}

\begin{tabular}{|l|l|l|l|l|l|l|}
\hline \multicolumn{6}{|l|}{ middle-old(n=50) } \\
\hline & normal BMI(n=31) & overweight BMI(19) & \\
\hline & normal & DM & p value & normal & DM & p value \\
\hline & $(\mathrm{n}=14)$ & $(\mathrm{n}=17)$ & & $(\mathrm{n}=9)$ & $(\mathrm{n}=10)$ & \\
\hline HR & $41.00 \pm 7.9$ & $31.18 \pm 9.01$ & $0.0025^{* *}$ & $33.01 \pm 8.03$ & $36.26 .18 \pm 9.0$ & 0.4217 \\
\hline
\end{tabular}

Data are mean \pm SD. HR-heart rate, BMI-body mass index.

$* \mathrm{p} \leq 0.05$ significant, $* * \mathrm{p} \leq 0.01$ very significant, $* * * \mathrm{p} \leq 0.0001$ very highly significant. 
Variance in heart rate and maximum predicted heart rate on stress test with changing bod...

These symbols indicate level of significant difference between BMI. It is calculated using unpaired student $t$ test.

Table .1.8 Comparison of mean $\%$ change in heart rate and $\%$ max pHR between young and middle old in normal and overweight BMI middle old subjects

\begin{tabular}{|c|c|c|c|c|c|c|c|c|}
\hline & \multicolumn{3}{|c|}{ normal BMI(n=28) } & \multirow[b]{2}{*}{$\mathrm{r}$ value } & \multicolumn{4}{|c|}{ overweight(n=18) } \\
\hline & young & middle-old & $\mathrm{p}$ value & & young & middle-old & $\mathrm{p}$ value & $\begin{array}{l}\mathrm{r} \\
\text { value }\end{array}$ \\
\hline & $(n=14)$ & $(n=14)$ & & & $(n=9)$ & $(n=9)$ & & \\
\hline HR & $47.3 \pm 3.5$ & $41.0 \pm 7.9$ & $0.010 * *$ & -0.926 & $25.53 \pm 5.56$ & $33.01 \pm 8.03$ & $0.0354^{*}$ & $\begin{array}{l}- \\
0.375\end{array}$ \\
\hline$\% \max \mathrm{p}(\mathrm{HR})$ & $91.14 \pm 6.11$ & $89.25 \pm 10.13$ & $0.0011 * *$ & -0.86 & $70.33 \pm 6.30$ & $88.81 \pm 12.44$ & 0.5548 & -0.03 \\
\hline
\end{tabular}

Data are mean \pm SD. HR-heart rate, BMI-body mass index, pHR-predicted heart rate.*p $\leq 0.05$ significant, $* * p \leq 0.01$ very significant, $* * * p \leq 0.0001$ very highly significant. These symbols indicate level of significant difference between BMI. It is calculated using unpaired student $t$ test

Fig 1.1

mean \% change in HR in young

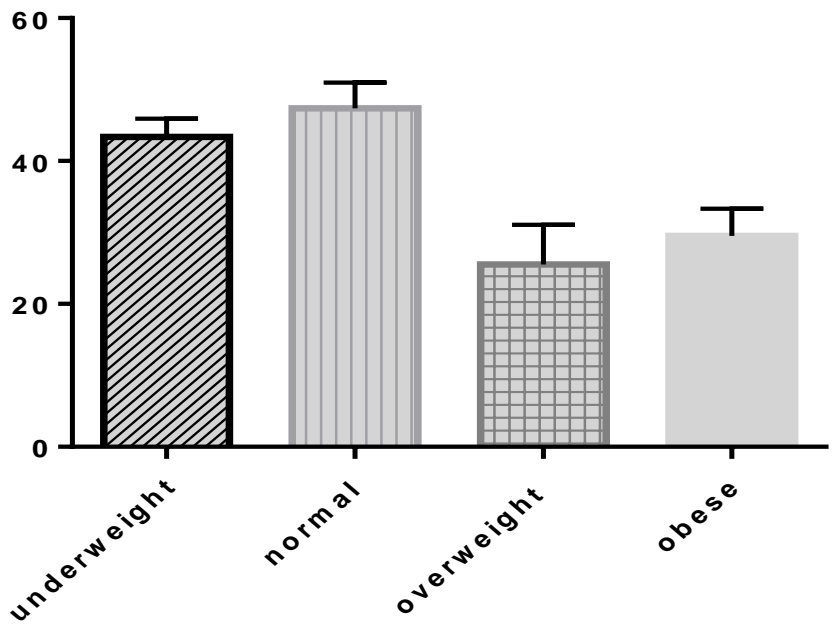

B M I
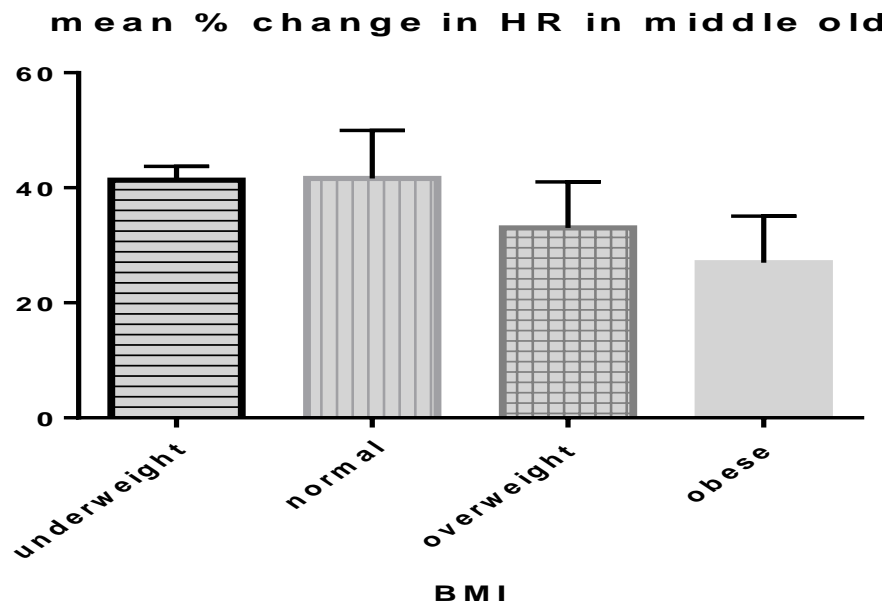

Left side figure shows the mean \% change in heart rate (HR) in young comparing to the mean \% change in HR in middle old. Both the figures illustrate the difference in underweight, normal, overweight, obese BMI subjects 
Fig 1.2

mean \% change in HR in normal BM I
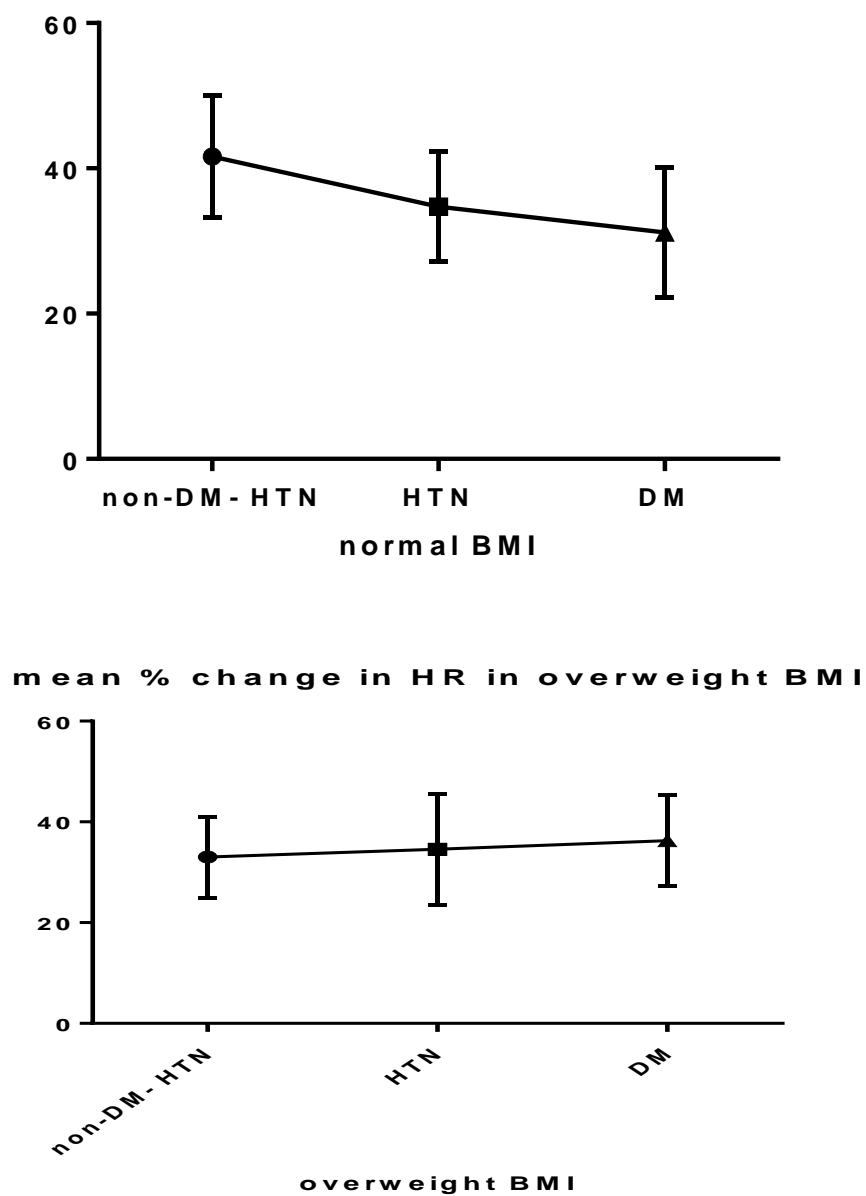

Left side figure shows the mean \% change in heart rate in normal BMI while right side figure shows the mean $\%$ change in heart rate in overweight BMI comparing between non type 2 diabetes mellitus - non hypertension ( non DM-HTN), hypertension (HTN), type 2 diabetes mellitus (DM)

Fig 1.3

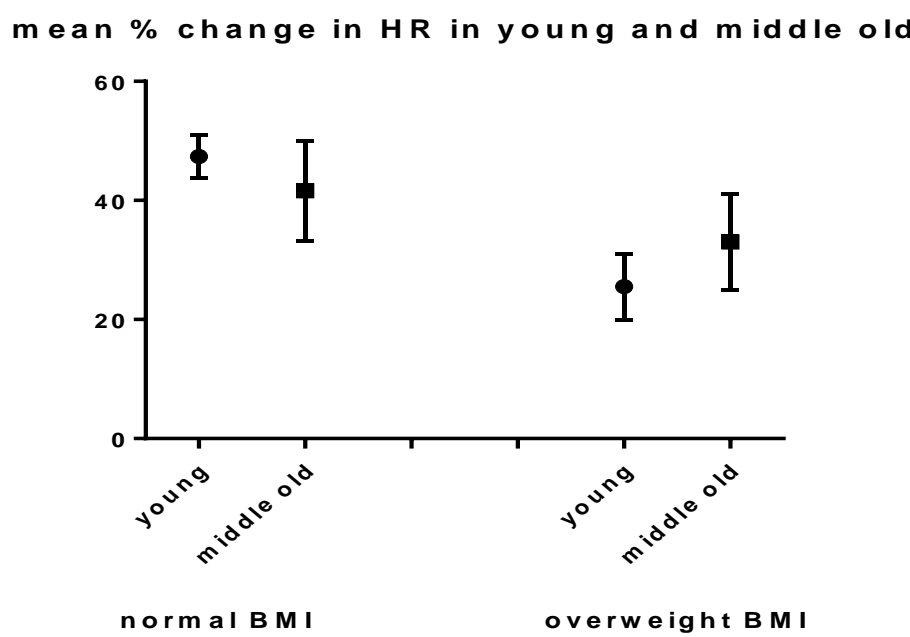

Shows the mean \% change in HR in young and middle old. Left portion describes the results in normal BMI while right shows the results in overweight BMI 
Variance in heart rate and maximum predicted heart rate on stress test with changing bod...

There was very high significant difference in pre-test \& after exercise value in HR in youngas well in middle old ( $\mathrm{p}$ value $<0.0001$ ) indicating that the cardiovascular system is put on stress with the increase in sympathetic and parasympathetic activity on doing the treadmill test.

On comparing the pre-test values i.e. the resting HR between different BMI there was very high significant difference in young ( $\mathrm{p}$ value $<0.0001$ ) and inmiddle old the difference was significant ( $\mathrm{p}$ value 0.0489). Table 1.4 illustrates that higher BMI subjects had a significantly higher resting HR as compared to that of lower BMI subjects.

The \% max pHR showed significant difference with change in BMI in young $(\mathrm{p}<0.0001)$ while there was no significant difference in middle old.

The mean $\%$ change in HR was significantly different on comparing between underweight, normal, overweight, obese BMI in young and in middle old ( $\mathrm{p}<0.0001$ and 0.0004 respectively). Fig 1.1 shows that there is comparatively high mean \% change in HR on doing the physical activity in underweight and normal BMI, while overweight and obese BMI subjects showed a minimal change.

The correlation coefficient between pre-test resting HR and BMI was positive in both young and middle-old (0.4)but showed a negative correlation on comparing BMI with its mean $\%$ change $(-0.8$ and -0.5). This states that resting heart rate significantly increases with increase in BMI. Conversely the percentage of change in heart rate significantly falls with increasing BMI.Likewise the \% max pHR showed a negative coefficient stating that it falls with the increasing BMI.

On comparing the resting HR and \% max predicted HR between non-HTN--DM and HTN subjects there was no significant difference in both normal and overweight BMI and this result was consistent on comparing the same between non-HTN-DM and DM subjects, except for resting HR in normal BMI subjects which showed a significant difference( $\mathrm{p}$ 0.007)

The mean \% change in HR was significantly different in normal BMI on comparing between non- HTN-DM, HTN-DM and this has been described in fig1.2. Interestingly there was no much difference on comparing the same in overweight subjects

The comparative study between young \& middle old in normal BMI showed a high significant change in mean \% change in HR and \% max pHR.(p 0.010 and 0.001). This states that significant changes occur in the functioning of heart as age progresses, however on comparing the same in overweight subjects there was no much change found between young and middle old(p 0.0354 and 0.554$)$. Also, the mean \% change in HR and \% max pHR was higher in middle old as compared to young as shown in fig 1.3 ,indicating that the detrimental effects on cardiovascular functioning do occur at a young age in overweight subjects.

\section{Discussion}

In this study we found that the overall prevalence of overweight and obesity was $41.37 \%$ in young and $44.08 \%$ in middle old subjects. In contradictory a study carried out in urban south India the overall prevalence of overweight was $10 \%$ and obesity was 5\% among 761 adolescents studied(12). While another study done to compare between higher and lower socio economic status in 5664 school children of 12-18 years of age prevalence of overweight was found to be $14.3 \%$ among boys and $9.2 \%$ among girls whereas the prevalence of obesity was $2.9 \%$ in boys and $1.5 \%$ in girls (13). The overall prevalence of overweight among adolescents varies between $10 \%$ and $30 \%(14)$. While in Balkan countries there was $43.8 \%$ prevalence of overweight /obese in the study conducted in Greece(15), a little lower than in India. This claims that there is a rising trend of overweight $\&$ obesity in India as that of the part of the world

In the present study we investigated on how the increase in BMI results in deterioration of cardiovascular functioning. The difference in pre-test \& after exercise values in HR proved that it was highly significant in both young and old as well in all bmi subjects. The finding was consistent in all age groups as well in all BMI groups.

During exercise there are a number of physiological mechanism that play a role in terms of increase in the blood flow to about 25 fold and oxygen delivery to the muscles(16). The increased blood flow to the muscles is due to increase in opening of blood capillaries, increase rate in flow of blood, release of local vasodilators resulting in the dilatation of the arterioles, increase in metabolism in muscles compensated by increase in cardiac output i.e. by increasing the heart rate and stroke volume, stimulation of the vasomotor centre leading to sympathetic and parasympathetic stimulation and contraction of veins leading to increased systemic filling pressure(16).

Increase in BMI is correlated with increase left ventricular (LV) mass and wall thickness (17). Human obesity is associated with impairment of sympathetic activation with increased sympathetic discharge at resting rate which contributes to the increased incidence of hypertension and cardiovascular complications in overweight subjects $(18,19)$. It is also responsible for impairment in the baroreceptor reflex of cardiac and peripheral control(19). 
Variance in heart rate and maximum predicted heart rate on stress test with changing bod...

As HR and maximum oxygen consumption by heart (VO2) are interrelated with each other, HR is used as a quantitative assessment tool during exercise (4). There is a direct relationship between oxygen consumption and activity intensity rise and between exercise intensity and heart rate during aerobic exercises. The oxygen consumption will increase and reach 7 to 8 times more than the rest while heart rate will reach the maximum with the maximum exercise intensity (20).

On comparing the value of pre-test resting HR and BMI there was highly significant difference between all BMI groups in young and in middle-old. The association between BMI and HR was positive. At rest, heart rate is called a resting heart rate. The higher resting heart rate indicated that heart must work harder to pump blood through the excess tissue. While the resting heart rate of an underweight and normal will be lower because the heart is stronger and can work more efficiently with each beat.

During exercise the young rely more on an increase in the ejection fraction (+11 ejection fraction units) with no cardiac dilatation (21). In the present study, on comparing these variables on exercise there was increase in HR with exercise but the increase was more in young as compared to that of old also incre ase was significantly more in underweight, \& normal BMI in age groups. In a similar study conducted earlier, it was found that during exercise, the old group had a lesser increase in heart rate $(+105 \%$ old versus $+166 \%$ young, a greater increase in end-diastolic volume index ( $+8 \%$ old versus $-10 \%$ young), a lesser fall in endsystolic volume index $(-0 \%$ old versus $-32 \%$ young), and a lesser increase in cardiac index $(+135 \%$ old versus $+189 \%$ young) (all $\mathrm{P}<.01$ young/old versus exercise stage), lesser increases in ejection fraction ( +3 ejection fraction units old versus +11 units young) and peak ejection rate $(+62 \%$ old versus $+119 \%$ young)(21). During exercise the ejection fraction was less than 0.60 in 45 per cent of subjects over age 60 as compared with 2 per cent of younger subjects $(\mathrm{P}<0.001)(22)$. Another study observed that there was age-related increase in stroke volume on diastolic filling was emphasized by the fact that at this high workload end-systolic volume was higher (end-systolic volume $[\mathrm{ml}]=3.09+0.65$ [age]; $\mathrm{r}=.45, \mathrm{p}=.003$ ) and ejection fraction lower (ejection fraction $=88.48-0.18$ [age] $\mathrm{r}=-.33, \mathrm{p}=.04)$ with increasing age $(23)$. A heart rate that does not increase adequately during exercise is associated with increased risk of death (24).

It has been shown that exercising at heart rates between $55 / 60 \%$ to $90 \%$ of maximum HR (or $50 \%$ to $85 \% \mathrm{VO} 2$ ) is an appropriate level of exercise intensity for improving cardiovascular fitness and reducing body fat(4,25-27).\% max pHR on comparing with BMI there was a significantly higher value in underweight, normal BMI as compared to overweight/ obese in both young and old although the difference being highly significant in young as compared to old.Also higher $\%$ max $\mathrm{pHR}$ was found in old as compared to young on exercise.

According to the Framingham Study, hypertension accounts for about one quarter of heart failure cases(28). Studies conducted to know the mechanism of adrenergic and reflex abnormalities has proven that Muscle sympathetic nerve activity (MSNA) was significantly $(\mathrm{P}:<0.01)$ greater in obese normotensive subjects $(49.1+/-3.0$ bursts per 100 heart beats) and in lean hypertensive subjects $(44.5+/-3.3$ bursts per 100 heart beats) than in lean normotensive control subjects (32.2+/-2.5 bursts per 100 heart beats); a further increase was detectable in individuals with the concomitant presence of obesity and hypertension $(62.1+/-3.4$ bursts per 100 heart beats) (29).Similarly, arterial plasma norepinephrine, an index of sympathetic drive, was increased in hypertensives compared to normotensives (mean +/- SE), 199 +/- 24 vs. 134 +/- 11 pg/ml, P less than 0.02(30).

On comparing the non-diabetic-hypertensive and hypertensive subjects we found that the resting value of HR, was significantly higher in hypertensive than in non-hypertensive group. On exercise the rise in HR, along with \% max predicted HR was more in non-hypertensive as compared to hypertensive. Observations in the Bogalusa Heart Study have shown an important correlation of clinical risk factors in early life with anatomic changes in the aorta and coronary vessels with atherosclerosis and cardiac and renal changes related to hypertension (31). Like an overweight and obese heart, there is increased workload on a hypertensive heart thus resulting in higher resting heart rate whereas during exercise it is the non-hypertensive heart have higher capacity to supply the extra lead of blood to the exercising muscles. We also compared the results of normal BMI hypertensive subjects with overweight BMI hypertensive subjects and it was found that there was hardly any difference in change In HR in overweight BMI subjects while significant change was present in normal BMI subjects . There is independent inverse association between cardio respiratory fitness levels and mortality risk in individuals with HTN regardless of BMI levels however the impact of fitness on the mortality rate is greater in the overweight and obese individuals compared to those of normal weight(32). In a study on school children,obese hypertensive students had higher resting heart rate than non-obese normotensive patients (85.9 vs 79.6 beats/min, $\mathrm{P}<.001$ ) (33). In normotensive obesity, it has been shown that renal sympathetic tone is doubled, however cardiac norepinephrine spillover (a measure of sympathetic activity in the heart) is only $50 \%$ of normal. While in obesity-related hypertension, there is a comparable elevation of renal norepinephrine spillover, and cardiac norepinephrine spillover is more than double that of normotensive obese(34). Evidence from direct intraneural recordings, found that the borderline hypertensive group had higher systolic ( $\mathrm{p}$ less than 0.01) and 
Variance in heart rate and maximum predicted heart rate on stress test with changing bod...

diastolic (p less than 0.05) blood pressures and increased sympathetic nerve activity independent of sodium intake(35)

Obesity in type-2 diabetic patients is a very common phenomenon and often termed as "Diabesity"(14).hyperinsulinemia and insulin resistance are the links that tie hypertension, obesity, and NIDDM togethe(36). Diabetes, obesity, hypertension, dyslipidaemia are grouped under one name "Metabolic syndrome (14).On comparing the non-hypertensive-diabetic and diabetic subjects the result was consistent as that of hypertensive except for one difference i.e. there was significant difference in resting HR, between diabetic and non-diabetic-hypertensive subject while the difference was not significant between hypertensive and non-diabetic-hypertensive group in normal BMI subjects. Thus we can conclude that higher work is done by the heart of a diabetic as compared to that of the non-diabetic. On exercise there was significant increase in HR in non- HTN-DM subjects as compared to DM subjects .Conversely in overweight subjects, the increase was more in DM as compared to non- HTN-DM subjects. Diabetic hearts exhibit signs of a progressive cardiomyopathy; increased fatty acid oxidation preceded reductions in carbohydrate oxidation along with decreased Post ischemic recovery of function (37).It has been proven, mean urinary norepinephrine excretion was higher in subjects classified as either hyperglycaemic (serum fasting glucose greater than or equal to $113 \mathrm{mg} / \mathrm{dl}$ ) and hyperinsulinemic (serum fasting insulin greater than or equal to $19 \mathrm{microIU} / \mathrm{ml})(\mathrm{p}=0.0023)$ or in subjects classified as either hyperglycaemic or hyperinsulinemic $(\mathrm{p}=0.0063)$ than the mean urinary norepinephrine excretion in normal subjects(38). An Evidence from microelectrode nerve recordings in healthy subjects showed that an acute rise in plasma insulin levels is known to increase intraneurally recorded muscle sympathetic activity $(39,40)$. The increases in muscle nerve sympathetic activity were significant ( $\mathrm{p}$ less than 0.001; ANOVA) throughout insulin infusion, with a slight further increase at the supraphysiological insulin concentration(40).Apparently healthy individuals with family history of type-2 diabetes mellitus comparatively have higher anthropometric values and lower physical fitness(41). We also compared the results of normal BMI diabetic subjects with overweight BMI diabetic subjects and the result was found to be consistent with that of non-hypertensivediabetic subjects.

Aging is associated with a mild increase in heart weight, and narrowing of the left ventricular outflow tract(42-44). In the resting aging heart, there are largely no alterations of systolic function, with preserved ejection fraction and stroke volume; because resting heart rate is unchanged or only minimally reduced with aging, cardiac output is also preserved(45). The plasma norepinephrine level, a measure of cardiovascular sympathetic nervous system activity, and the mean arterial blood pressure increased wtih age $(r=0.68$ and 0.67 , respectively, both $\mathrm{p}<0.001) 0(46,47)$. Respiratory variation of heart rate during beta-adrenergic blockade, an index of cardiac parasympathetic nervous system activity, was reduced in older subjects $(r=-0.54, p<$ $0.001)$ thus stating that there is sympathetic nervous system and parasympathetic nervous system compensation of cardiovascular function in response to an age-related decrease in baroreceptor sensitivity(47).

We found that there was significant difference of mean $\%$ change of all $\mathrm{HR}$ and $\%$ max pHR between young and middle old in overweight bmi subject while there was significant difference in normal bmi subjects. Thus we can hypothesize that there is significant difference in the structural and physiological functional of heart in young and middle old subjects of normal BMI, whereas in overweight BMI it is almost the same concluding that detrimental effects of cardiovascular disease do begin at a younger age in overweight and obese individuals, however needs more research to prove it. In the Baltimore Longitudinal Study of Aging. , during vigorous exercise $(125 \mathrm{~W})$, there was an age-related increase in end-diastolic volume and stroke volume, and an age-related decrease in heart rate(23). The heart becomes slightly hypertrophic and hyporesponsive to sympathetic (but not parasympathetic) stimuli, so that the exercise-induced increases in heart rate and myocardial contractility are blunted in older hearts(48). A mental stress programme and isometric exercise gave significant increases in heart rate and blood pressure for all age groups(49). Hypothalamic regulation of baroreceptor reflex sensitivity becomes altered with age with alterations at the afferent, central neural, efferent, effector organ portions of the reflex arch and cardiopulmonary vagal afferents resulting in decrease in sympathoexcitatory responses $(48,50-53)$.

Our study had limitations in terms of 1) the sample size of non-hypertensive-diabetic was lower.2) there was no demographic data about cardiovascular mortality in the specific population3) other risk factors of cardiovascular disease were not considered4) other anthropometric measurements like waist hip ratio to know the body fat distribution and skin fold thickness related to overweight and obesity were not taken into consideration.

\section{Conclusion}

Increase in BMI result in alteration of the autonomic function of the heart. At rest there is sympathetic over activity while on exercise due to anatomical and physiological capacity, it cannot bear the increasing workload. This is consistent in both young as well as old. However age acts as a 
Variance in heart rate and maximum predicted heart rate on stress test with changing bod...

cumulative factor to obesity resulting in further deterioration.Diabetes and hypertension are other factors which also affect the normal functioning of heart.

\section{Acknowledgement}

Sincere thanks and gratitude to the cardiology department, Goa medical college, Bambolim, Goa, India for the allowing us to make use of the departmental treadmill and for all the help they provided to conduct this study.

\section{References}

[1]. India set to be "heart disease capital of world", say doctors. Express News Service [Internet]. 2012 Sep 29;2. Available from: http://archive.indianexpress.com/news/india-set-to-be--heart-disease-capital-of-world--say-doctors/1009607/2

[2]. Sharma, D. C. India's no. 1 killer: heart disease. India Today New Delhi. 2010;

[3]. Ciampi Q, Borzillo G, Barbato E, Petruzziello B, Betocchi S, Villari B. Diastolic function and BNP changes during exercise predict oxygen consumption in chronic heart failure patients. Scand Cardiovasc J SCJ [Internet]. 2009 Feb;43(1):17-23. Available from: https://search.ebscohost.com/login.aspx?direct=true\&db=cmedm\&AN=18609042\&site=eds-live

[4]. Mercer JA, Dufek JS, Bates BT. Analysis of Peak Oxygen Consumption and Heart Rate During Elliptical and Treadmill Exercise. J Sport Rehabil [Internet]. $2001 \mathrm{Feb} ; 10(1): 48-56$. Available from:

https://search.ebscohost.com/login.aspx?direct=true\&db=asx\&AN=6193882\&site=eds-live

[5]. Hitzhusen JC, Hickler RB, Alpert JS, Doherty PW. Exercise testing and hemodynamic performance in healthy elderly persons. Am J Cardiol. 1984 Nov 1;54(8):1082-6.

[6]. Petriz BA, Almeida JA, Gomes CPC, Ernesto C, Pereira RW, Franco OL. Exercise performed around MLSS decreases systolic blood pressure and increases aerobic fitness in hypertensive rats. BMC Physiol [Internet]. 2015; Available from: https://search.ebscohost.com/login.aspx?direct=true\&db=edsgih\&AN=edsgcl.405991525\&site=eds-live

[7]. Luo H-C, Dimaano VL, Kembro JM, Hilser A, Hurtado-de-Mendoza D, Pozios I, et al. Exercise Heart Rates in Patients with Hypertrophic Cardiomyopathy. Am J Cardiol [Internet]. 2015 Jan 13; Available from:

https://search.ebscohost.com/login.aspx?direct=true\&db=edselp\&AN=S0002914915006438\&site=eds-live

[8]. Adabag S, Pierpont GL. Exercise heart rate recovery: analysis of methods and call for standards. Heart Br Card Soc [Internet]. 2013 Dec;99(23):1711-2. Available from: https://search.ebscohost.com/login.aspx?direct=true\&db=cmedm\&AN=23591670\&site=edslive

[9]. [9]. Palatini P. Exercise haemodynamics in the normotensive and the hypertensive subject. Clin Sci Lond Engl 1979. 1994 Sep;87(3):275-87.

[10]. Rodeheffer RJ, Gerstenblith G, Becker LC, Fleg JL, Weisfeldt ML, Lakatta EG. Exercise cardiac output is maintained with advancing age in healthy human subjects: cardiac dilatation and increased stroke volume compensate for a diminished heart rate. Circulation. $1984 \mathrm{Feb} ; 69(2): 203-13$.

[11]. Lissin LW, Gauri AJ, Froelicher VF, Ghayoumi A, Myers J, Giacommini J. The prognostic value of body mass index and standard exercise testing in male veterans with congestive heart failure. J Card Fail. 2002 Aug;8(4):206-15.

[12]. Bengalorkar GM, Deepthi R, Muninarayan C, Ravishankar S. PREVALENCE OF OVERWEIGHT AND OBESITY AMONG ADOLESCENT SCHOOL GOING CHILDREN (12-15YEARS) IN URBAN AREA, SOUTH INDIA. Int J Cur Res Rev. 2012;4(20).

[13]. Goyal RK, Shah VN, Saboo BD, Phatak SR, Shah NN, Gohel MC, et al. Prevalence of overweight and obesity in Indian adolescent school going children: its relationship with socioeconomic status and associated lifestyle factors. J Assoc Physicians India. 2010 Mar;58:151-8.

[14]. Kalra S, Unnikrishnan A. Obesity in India: The weight of the nation. J Med Nutr Nutraceuticals. 2012;1(1):37.

[15]. Nikolaidis PT, Ingebrigtsen J. The relationship between body mass index and physical fitness in adolescent and adult male team handball players. Indian J Physiol Pharmacol [Internet]. 2013 [cited 2015 Mar 20];57(4):361-71. Available from: http://www.researchgate.net/profile/Jorgen_Ingebrigtsen/publication/259145245_The_relationship_between_body_mass_index_and _physical_fitness_in_adolescent_and_adult_male_team_handball_players/links/0046352a069f965812000000.pdf

[16]. John E. Hall, Arthur C. Guyton. Cardiovascular System in Exercise. In: Guyton of Med\& Hall: Textbook ical Physiology,. 12th ed. Saunders; 2010

[17]. Wong CY, O'Moore-Sullivan T, Leano R, Byrne N, Beller E, Marwick TH. Alterations of left ventricular myocardial characteristics associated with obesity. Circulation. 2004 Nov 9;110(19):3081-7.

[18]. Scherrer U, Randin D, Tappy L, Vollenweider P, Jéquier E, Nicod P. Body fat and sympathetic nerve activity in healthy subjects. Circulation. 1994 Jun;89(6):2634-40.

[19]. Grassi G, Seravalle G, Cattaneo BM, Bolla GB, Lanfranchi A, Colombo M, et al. Sympathetic activation in obese normotensive subjects. Hypertension. 1995 Apr;25(4 Pt 1):560-3.

[20]. Shakerian S, Goomar M, Nikbakht M. Comparison of Submaximal aerobic exercise effects in different intensities on heart rate and oxygen consumption during arm and leg exercise. Ann Biol Res [Internet]. 2012 Nov;3(7):3287-91. Available from: https://search.ebscohost.com/login.aspx?direct=true\&db=cxh\&AN=88865702\&site=eds-live

[21]. Stratton JR, Levy WC, Cerqueira MD, Schwartz RS, Abrass IB. Cardiovascular responses to exercise. Effects of aging and exercise training in healthy men. Circulation. 1994 Apr;89(4):1648-55.

[22]. Port S, Cobb FR, Coleman RE, Jones RH. Effect of age on the response of the left ventricular ejection fraction to exercise. N Engl J Med. 1980 Nov 13;303(20):1133-7.

[23]. Rodeheffer RJ, Gerstenblith G, Becker LC, Fleg JL, Weisfeldt ML, Lakatta EG. Exercise cardiac output is maintained with advancing age in healthy human subjects: cardiac dilatation and increased stroke volume compensate for a diminished heart rate. Circulation. $1984 \mathrm{Feb} ; 69(2): 203-13$.

[24]. Miller TD. Exercise treadmill test: estimating cardiovascular prognosis. Cleve Clin J Med. 2008 Jun;75(6):424-30

[25]. Garber CE, Blissmer B, Deschenes MR, Franklin BA, Lamonte MJ, Lee I-M, et al. American College of Sports Medicine position stand. Quantity and quality of exercise for developing and maintaining cardiorespiratory, musculoskeletal, and neuromotor fitness in apparently healthy adults: guidance for prescribing exercise. Med Sci Sports Exerc. 2011;43(7):1334-59.

[26]. American College of Sports Medicine. ACSM's guidelines for exercise testing and prescription. Lippincott Williams \& Wilkins; 2013. 
Variance in heart rate and maximum predicted heart rate on stress test with changing bod...

[27]. Gibbons RJ, Balady GJ, Beasley JW, Bricker JT, Duvernoy WF, Froelicher VF, et al. ACC/AHA guidelines for exercise testing: executive summary. A report of the American College of Cardiology/American Heart Association Task Force on Practice Guidelines (Committee on Exercise Testing). Circulation. 1997 Jul 1;96(1):345-54.

[28]. Kannel WB, Cobb J. Left ventricular hypertrophy and mortality--results from the Framingham Study. Cardiology. 1992;81(45):291-8.

[29]. Grassi G, Seravalle G, Dell'Oro R, Turri C, Bolla GB, Mancia G. Adrenergic and reflex abnormalities in obesity-related hypertension. Hypertension. 2000 Oct;36(4):538-42.

[30]. Egan B, Panis R, Hinderliter A, Schork N, Julius S. Mechanism of increased alpha adrenergic vasoconstriction in human essential hypertension. J Clin Invest [Internet]. 1987 Sep;80(3):812-7. Available from: http://www.ncbi.nlm.nih.gov/pmc/articles/PMC442307/

[31]. Berenson GS. Childhood risk factors predict adult risk associated with subclinical cardiovascular disease. The Bogalusa Heart Study. Am J Cardiol. 2002 Nov 21;90(10C):3L - 7L

[32]. Kokkinos P, Faselis C, Myers J, Manolis T, Pittaras A, Kyritsi F, et al. MORTALITY RISK AND EXERCISE CAPACITY ASSOCIATIONS IN HYPERTENSIVES ACCORDING TO BMI LEVELS: 5D. 01. J Hypertens. 2010;28:e229.

[33]. Sorof JM, Poffenbarger T, Franco K, Bernard L, Portman RJ. Isolated systolic hypertension, obesity, and hyperkinetic hemodynamic states in children. J Pediatr. 2002 Jun;140(6):660-6.

[34]. Esler M. The sympathetic system and hypertension. Am J Hypertens. 2000 Jun;13(6 Pt 2):99S - 105S

[35]. Anderson EA, Sinkey CA, Lawton WJ, Mark AL. Elevated sympathetic nerve activity in borderline hypertensive humans. Evidence from direct intraneural recordings. Hypertension. 1989 Aug;14(2):177-83.

[36]. Daly PA, Landsberg L. Hypertension in obesity and NIDDM. Role of insulin and sympathetic nervous system. Diabetes Care. 1991 Mar;14(3):240-8.

[37]. Aasum E, Hafstad AD, Severson DL, Larsen TS. Age-dependent changes in metabolism, contractile function, and ischemic sensitivity in hearts from db/db mice. Diabetes. 2003 Feb;52(2):434-41.

[38]. Troisi RJ, Weiss ST, Parker DR, Sparrow D, Young JB, Landsberg L. Relation of obesity and diet to sympathetic nervous system activity. Hypertension. 1991 May;17(5):669-77.

[39]. Anderson EA, Hoffman RP, Balon TW, Sinkey CA, Mark AL. Hyperinsulinemia produces both sympathetic neural activation and vasodilation in normal humans. J Clin Invest. 1991 Jun;87(6):2246-52.

[40]. Berne C, Fagius J, Pollare T, Hjemdahl P. The sympathetic response to euglycaemic hyperinsulinaemia. Evidence from microelectrode nerve recordings in healthy subjects. Diabetologia. 1992 Sep;35(9):873-9.

[41]. Padaki S, Vijayakrishna K, Dambal A, Ankad R, Manjula R, Surekharani C, et al. Anthropometry and physical fitness in individuals with family history of type-2 diabetes mellitus: A comparative study. Indian J Endocrinol Metab. 2011 Oct;15(4):327-30.

[42]. GOOR D, LILLEHEI CW, EDWARDS JE. THE “SIGMOID SEPTUM.” Am J Roentgenol [Internet]. 1969 Oct 1 [cited 2015 Mar 27];107(2):366-76. Available from: http://dx.doi.org/10.2214/ajr.107.2.366

[43]. Grassi G, Seravalle G, Bertinieri G, Turri C, Dell'Oro R, Stella ML, et al. Sympathetic and reflex alterations in systo-diastolic and systolic hypertension of the elderly. J Hypertens. 2000 May;18(5):587-93.

[44]. O'Leary DH, Polak JF, Kronmal RA, Manolio TA, Burke GL, Wolfson SK. Carotid-artery intima and media thickness as a risk factor for myocardial infarction and stroke in older adults. Cardiovascular Health Study Collaborative Research Group. N Engl J Med. 1999 Jan 7;340(1):14-22.

[45]. Rywik TM, Blackman MR, Yataco AR, Vaitkevicius PV, Zink RC, Cottrell EH, et al. Enhanced endothelial vasoreactivity in endurance-trained older men. J Appl Physiol Bethesda Md 1985. 1999 Dec;87(6):2136-42.

[46]. Messerli FH, Frohlich ED, Suarez DH, Reisin E, Dreslinski GR, Dunn FG, et al. Borderline hypertension: relationship between age, hemodynamics and circulating catecholamines. Circulation. 1981 Oct;64(4):760-4.

[47]. Pfeifer MA, Weinberg CR, Cook D, Best JD, Reenan A, Halter JB. Differential changes of autonomic nervous system function with age in man. Am J Med. 1983 Aug;75(2):249-58.

[48]. Ferrari AU, Radaelli A, Centola M. Invited review: aging and the cardiovascular system. J Appl Physiol Bethesda Md 1985. 2003 Dec;95(6):2591-7.

[49]. Johansson SR, Hjalmarson A. Age and sex differences in cardiovascular reactivity to adrenergic agonists, mental stress and isometric exercise in normal subjects. Scand J Clin Lab Invest. 1988 Apr;48(2):183-91.

[50]. Tanabe S, Buñag RD. Aging escalates baroreceptor reflex suppression by the posterior hypothalamus in rats. Hypertension. 1991 Jan; 17(1):80-90.

[51]. Hunt BE, Farquhar WB, Taylor JA. Does reduced vascular stiffening fully explain preserved cardiovagal baroreflex function in older, physically active men? Circulation. 2001 May 22;103(20):2424-7.

[52]. Gerstenblith G, Frederiksen J, Yin FC, Fortuin NJ, Lakatta EG, Weisfeldt ML. Echocardiographic assessment of a normal adult aging population. Circulation. 1977 Aug;56(2):273-8.

[53]. Miller TR, Grossman SJ, Schectman KB, Biello DR, Ludbrook PA, Ehsani AA. Left ventricular diastolic filling and its association with age. Am J Cardiol. 1986 Sep 1;58(6):531-5. 